\title{
HISTÓRIA DO ENSINO E DISCURSOS POLÍTICO-EDUCACIONAIS NA EDUCAÇÃO DE SÃO PAULO
}

\author{
Francisco Carlos Franco ${ }^{1}$ \\ Rosália Maria Netto Prados ${ }^{2}$
}

\begin{abstract}
RESUMO
Este trabalho apresenta um estudo sobre a história do ensino em São Paulo, sob a perspectiva dos discursos político-educacionais. Nas práticas sociais e educacionais, manifestam-se discursos que revelam sistemas de valores e saberes da sociedade, ao longo do processo histórico da educação. Nas situações de comunicação, diferentes discursos são produzidos e fazem parte de uma rede de significações construída pelos sujeitos, num determinado contexto cultural, espaço e tempo. Propõe-se, numa abordagem qualitativa, uma descrição do processo histórico da educação e uma análise discursiva das políticas educacionais que se constituíram na rede pública de ensino, desde o governo de Franco Montoro até a reorganização do sistema educacional de São Paulo, iniciada no governo de Mário Covas.

Palavras-chave: Discursos político-educacionais; Educação de São Paulo; História da Educação; História e políticas de ensino.
\end{abstract}

\section{HISTORY OF EDUCATION AND POLITICAL-EDUCATIONAL SPEECHES IN EDUCATION OF SÃO PAULO}

\begin{abstract}
This paper presents a study on the history of education in São Paulo, from the perspective of political-educational discourses. In social and educational practices, which manifested speeches that reveal the values systems of and knowledge of society, along the historical process of education. In situations of communication, different discourses are produced and are part of the network of meanings constructed by individuals in a given cultural context, space and time. It is proposed, in a qualitative approach, a description of the historical process of education and a discourse analysis of educational policies that formed in public schools since the government Franco Montoro until the reorganization of the educational system of São Paulo, in the government of Mário Covas.

Keywords: Political-educational discourses; Education of São Paulo; History of education; History and teaching politics.
\end{abstract}

\section{Introdução}

Este estudo focaliza marcos da história da educação em São Paulo, a partir do governo Franco Montoro, para uma reflexão sobre os discursos político-educacionais e pedagógicos que se configuram no cenário mundial do neoliberalismo de mercado. No campo da educação, e respectivas práticas sociais e institucionais, manifestam-se discursos que revelam os sistemas de valores e saberes da sociedade, ao longo de seu processo histórico. São reflexões sobre mudanças e renovações na educação e sua relação com os discursos político-educacionais. 
O estudo do contexto histórico possibilita uma nova perspectiva de análise dos discursos da educação, pois, atualmente, na sociedade brasileira evidenciam-se contradições que se acentuaram a partir da era tecnológica com seus avanços e com seu poder multiplicador, além da aplicabilidade das novas tecnologias da informação a todas as tarefas humanas, além da imposição de novas regras econômicas e, consequentemente, a exigência de novos perfis no mercado de trabalho. Na educação de São Paulo, existem programas constituídos segundo esses discursos, como por exemplo, os programas de formação continuada de professores, em que se apresentam discursos pedagógicos sobre a inserção das novas tecnologias na sala de aula, etc. E, dessa maneira, hoje, os discursos político-educacionais refletem os sistemas de valores da sociedade atual.

A transmissão, conservação, transformação e aprendizagem da cultura realizam-se através das práticas sociais que, por sua vez, organizam-se segundo processos discursivos. Segundo Pais (1997, p. 237), saber e significação articulam-se no processo de produção discursiva refletindo o sistema de valores de uma comunidade. Esta perspectiva, de análise discursiva, possibilita a reconstrução do processo histórico do discurso políticoeducacional, para um estudo da constituição dos sujeitos e das relações de linguagem, ou seja, da formação discursiva, segundo Foucault (1995) além dos processos de construção do 'saber social', ou seja, do saber compartilhado.

Um discurso, segundo Pais (1993), é decorrente dos discursos que o precederam e a produção de um discurso específico só ocorre quando são utilizados os signos e as leis combinatórias que pertencem aos demais membros de determinado grupo, já que a experiência individual, em sua alta especificidade, é única e intraduzível e só será inteligível aos outros apenas quando traduzida em termos do "consenso" desse grupo. Para Pais (1997), os sistemas e discursos são historicamente determinados e geograficamente delimitados, pois a visão de mundo de uma comunidade sociocultural e linguística, bem como sua ideologia e sistema de valores, acha-se sempre em processo de (re)formulação e um constante processo de vir a ser que paradoxalmente transmite a seus membros o sentido de estabilidade e continuidade, ou melhor, os processos culturais são apreendidos no convívio social.

Para Foucault (1998), a linguagem é uma ferramenta humana arbitrária, entendida como um meio neutro de comunicação; são evidentes em sua obra as críticas ao lugar do Sujeito na filosofia moderna: uma representação de sujeito que surgiu a partir de uma representação de sua origem e olhar. Portanto, a linguagem científica se esforça por converter-se, tanto quanto possível, num registro transparente do olhar observador, sob um ponto de vista, ou melhor, numa ordem histórica e 'visível'. É nessa ordem, histórica e espacialmente determinada, que se constituem os saberes empíricos, teorias, e suas interpretações, ou seja, através do crivo de um olhar, ou seja, de uma linguagem.

Segundo Rabinow \& Dreyfus (1995, p.121), Foucault apresentou uma história de problematizações a partir das quais se constituem as práticas sociais. Justificam-se, portanto, essas considerações sobre Foucault, que pode ser lido de muitas maneiras, sobretudo pelo impacto de suas ideias no modo de pensar contemporâneo. E para que se possa refletir sobre a educação de São Paulo e sobre a constituição dos discursos políticoeducacionais, a seguir apresenta-se uma parte da história e problematizações da educação.

\section{A busca pela democratização do sistema educacional - Governo Montoro (de 15 de março de 1983 a 15 de março de 1987)}

Para se entender a configuração dos discursos político-educacionais, é necessária a descrição do cenário mundial. A reorganização do capitalismo no mundo, para a 
globalização da economia, bem como o discurso do neoliberalismo de mercado e das mudanças técnico-científicas exigem novas agendas, novas ações, bem como novos discursos dirigidos à educação, sobretudo a partir da década de 1980. Evidencia-se uma nova configuração estrutural e educacional, por meio de percepções histórico-críticas, em que se caracterizaram dois paradigmas de modernização capitalista-liberal: o paradigma da liberdade econômica, da eficiência e da qualidade e o paradigma da igualdade (LIBÂNEO, OLIVEIRA E TOSCHI, 2009, p.96).

Em São Paulo, André Franco Montoro foi eleito governador do estado de São Paulo, em1982, estando à frente do governo no período entre 1983 a 1987. Sua eleição, como a de outros governadores de oposição, foi um marco na transição democrática na década de 1980, pois:

Os governantes eleitos dispunham de uma legitimidade nunca antes alcançada, o que lhes deu liberdade para elaborar e implementar políticas educacionais; autonomia reforçada pela inexistência ou desarticulação de diretrizes federais (BIOTO, 2000, p.165).

Em seu programa de governo, Montoro propõe para a educação uma ampla reforma administrativa, com o objetivo de racionalizar e descentralizar os recursos da educação, o que viria acompanhado da autonomia administrativa das instâncias intermediárias do sistema de ensino, por meio das Divisões Regionais e Delegacias de Ensino. Essas ações, decorrentes dos discursos que se constituíram no contexto da modernização capitalistaliberal, visavam propiciar uma melhoria na qualidade do ensino e nas condições de trabalho dos professores.

Com relação às questões de ordem pedagógica, aquele foi o período em que se iniciou a discussão sobre a reforma curricular para o ensino de $1^{\circ}$ e $2^{\circ}$ graus da Rede Pública de Ensino paulista, que objetivava substituir os antigos Guias Curriculares, elaborados sob a orientação dos preceitos da Lei 5692/ 71.

A condução do processo de reorientação curricular ficou sob a responsabilidade da CENP - Centro de Estudos e Normas Pedagógicas, órgão vinculado à Secretaria de Educação, responsável pelo encaminhamento da política educacional do estado. No início, nos anos de 1984 e 1985, foi realizada uma ampla discussão sobre as diretrizes curriculares, com participação de especialistas e da equipe técnica da CENP, processo este que desencadeou a publicação de uma versão preliminar em 1986, que foi apresentada para os professores da rede para discussão e propostas de alteração nos dias 27,28 e 29 de julho.

Segundo Palma Filho (2003), a reforma curricular iniciada em 1984 foi orientada por um diagnóstico dos conteúdos curriculares e do desenvolvimento do trabalho pedagógico nas escolas, constatou-se:

1. O tratamento dos conteúdos curriculares desconhece e/ou desconsidera as características do meio cultural da maioria dos alunos $[\ldots]$;

2. A transposição de modelos curriculares estrangeiros tem levado a escola a um alheamento em relação às nossas raízes históricas e culturais $[\ldots]$;

3. O desenvolvimento dos conteúdos curriculares de forma mecânica, estanque, segmentada, compromete a unidade curricular e deixa lacunas na formação do educando; 
4. A avaliação, ao invés de ser um recurso de aprimoramento do aluno, torna-se assunto de competência do professor, cujos critérios e procedimentos adotados não costumam ser discutidos;

5. A reprovação, usada por alguns para "melhorar a qualidade do ensino", muitas vezes castiga o aluno [...];

6. A discriminação dos alunos das camadas populares em razão de sua maneira de vestir e expressar-se, que, por ser diferente da do professor é considerada imprópria e inadequada (PALMA FILHO, 2003, p. 24-25).

A concretização do processo de reestruturação curricular, com a publicação da versão final das Propostas Curriculares, não se deu no governo Montoro, estendeu-se no governo Quércia, quando, em 1988, as propostas foram divulgadas e disponibilizadas ao corpo docente. Vale lembrar que as discussões sobre as Propostas Curriculares estão diretamente ligadas à criação do Ciclo Básico - $\mathrm{CB}$, instituído pelo Decreto Estadual $\mathrm{n}^{\circ}$ 21.833, de 28 de dezembro de 1983, que tinha como objetivo diminuir os índices de evasão e repetência no então chamado Primeiro Grau.

O discurso político-educacional que se manifestou após essa proposta se sustentou na ideia de que fossem oferecidas melhores oportunidades para o processo de alfabetização, principalmente, para as crianças das classes populares, que precisavam de mais de um ano para serem alfabetizadas.

Assim, as antigas $1^{a}$ e $2^{a}$ séries do Primeiro Grau passaram a ser cursadas de maneira contínua e o aluno não podia ser reprovado de uma série para outra. Com a implantação do CB, Ciclo Básico, algumas medidas estruturais foram efetivadas, procurando dar suporte ao projeto, entre as quais destacamos: a oferta de duas horas diárias de apoio pedagógico suplementar aos alunos com dificuldade de aprendizagem, a realização de reuniões de professores em horas extraordinárias e recompensas na carreira dos docentes que atuassem com turmas do CB. Já é possível perceber-se um discurso político-educacional intercedendo no discurso pedagógico, que se caracterizava como excludente.

Segundo Alvarez (1999, p.74), Foucault enfatiza que a produção do discurso é indissociável de uma série de procedimentos de controle, de seleção, de organização e de redistribuição dos enunciados e dos sujeitos, procedimentos estes voltados para afastar os poderes e os perigos do discurso, para dominar seu aparecimento aleatório, para esquivar sua própria materialidade. "O discurso não remete assim, exclusivamente, à ordem das leis, mas, sobretudo ao campo das lutas" (ALVAREZ, 1999, p. 74).

Também foram realizados encontros e cursos de formação para os professores, movidos por uma vontade política, com vistas à mudança qualitativa na prática docente, em duas perspectivas: nos aspectos teóricos vinculados às concepções mais atuais de alfabetização e na prática pedagógica, sendo que:

A linha de formação contínua dos professores para o trabalho desseriado do CB foi extensiva, por meio da transmissão dos programas do Projeto Ipê e da discussão monitorada de pequenos grupos através de textos sobre os temas dos programas em telepostos. Essa linha de formação, embora tenha a vantagem de atingir grandes contingentes em curto período, é um trabalho de superfície, funcionando mais como divulgação de ideias e propostas (DURAN, 2003, p.65).

Vários aspectos, segundo Duran (2003), dificultaram o desenvolvimento do projeto, como a falta de um coordenador pedagógico para orientar o trabalho e articular o corpo 
docente, a rotatividade de professores da rede, o alto número de alunos por classe, entre outros. Porém, não podemos deixar de pontuar os avanços que o $\mathrm{CB}$ propiciou, principalmente na discussão sobre os aspectos teóricos e metodológicos e dos conteúdos mais adequados à clientela escolar, além do que "No plano qualitativo, os primeiros dados divulgados no ano de 1987 apontavam um significativo avanço em relação ao aproveitamento escolar." (PALMA FILHO, 2003, p.24).

Outras ações foram realizadas no governo Montoro, mas muitas das propostas iniciais de seu plano de governo voltadas para a educação não chegaram a ser implantadas, como a descentralização do sistema de ensino, a regionalização dos concursos para efetivação dos professores.

\section{A Jornada Única no Ciclo Básico - Governo Quércia (de 15 de março de 1987 a 15 de março de 1991)}

Em 1986, Orestes Quércia é eleito governador do Estado de São Paulo, sendo empossado em março de 1987, e tendo permanecido no cargo até 1991. Em seu projeto de governo, estabelecem-se as diretrizes para a educação pública paulista que, entre outros aspectos, previa o desenvolvimento de ações administrativas e educacionais integradas com os municípios, revitalização da formação e capacitação dos professores e valorização do quadro do magistério.

Foi em seu governo que se deu a continuidade ao processo de reformulação dos currículos escolares, como também permaneceu a discussão sobre o Ciclo Básico, projeto este que foi alvo de muitas críticas e polêmicas no governo anterior, mas o impasse agora não estava na passagem sem a possibilidade de reprovação do aluno da $1^{\mathrm{a}}$ para a $2^{\mathrm{a}}$ série do Primeiro Grau, mas na extensão dos ciclos para as outras séries, o que só foi efetivado em gestões posteriores.

O discurso político-educacional vai orientar diferentes realizações em que se configuraram os discursos pedagógicos, caracterizados pelas ações descritas a seguir.

A municipalização do Ensino de Primeiro Grau, hoje, Ensino Fundamental, que teve uma forte valorização na gestão de Mário Covas (1995-1999), foi impulsionada, embora de maneira tímida, pela gestão Quércia, que instituiu o Programa de Municipalização do Ensino, por meio do Decreto no 30.375, de 13 de setembro de 1989. Também se destacaram naquele período: a criação do CEFAM - Centro Específico para a Formação do Magistério; projetos para o curso noturno e supletivo; descentralização da função pedagógica, com a criação das Oficinas Pedagógicas nas Delegacias de Ensino, entre outros. A política educacional do governo Quércia, foi assim sintetizada:

\footnotetext{
Após seis meses de gestão as diretrizes recaem, resumidamente no ensino regular, na democratização e na descentralização. A democratização seria concretizada no fortalecimento dos Grêmios Estudantis, APMs e Conselhos de Escola. A descentralização encontraria forma na parceria com os municípios e na descentralização das Delegacias de Ensino (BIOTO, 2000, p.173).
}

Em 1988, por intermédio do Decreto $\mathrm{n}^{\circ} 28.170$, de 21 de janeiro, o governo institui a Jornada Única Discente e Docente, ampliando a permanência dos alunos do Ciclo Básico para seis horas/ aula diárias de estudo na escola, distribuídas entre o professor alfabetizador e os professores especialistas em Educação Artística e Educação Física.

A Jornada Única, jornada de 40 horas para o professor alfabetizador, ficou concentrada numa única escola, sendo 26 horas com alunos em sala de aula e 6 horas de 
Horário de Trabalho Pedagógico - HTP, também em reuniões de estudo e discussão com seus pares. As oito horas restantes ficaram para planejamento e preparação de aulas em local de livre escolha.

Para orientar o trabalho pedagógico, o CB a partir da implantação da Jornada Única, passou a contar com um Coordenador Pedagógico, função esta que era preenchida por um professor eleito entre os docentes da unidade escolar e com comprovada experiência docente nas séries iniciais do Primeiro Grau. A indicação do Coordenador Pedagógico para o CB devia ser referendada pelo Conselho de Escola, cabendo a este profissional organizar o trabalho dos professores do CB e articulá-lo com os professores de $3^{\mathrm{a}}$ e $4^{\mathrm{a}}$ séries.

Percebe-se nessas ações, que os discursos veiculados manifestam nas suas subjacências relações de interdiscursividade, segundo o paradigma da eficiência e da qualidade.

Alguns meses após a implantação da Jornada Única mesmo com um balanço bastante otimista dos resultados alcançados, porém ainda havia aspectos que se apresentavam como pontos de estrangulamento do processo, entre os quais:

A falta de comprometimento efetivo dos diretores das escolas, muitos deles resistindo à medida e pouco envolvidos com questões pedagógicas; As dificuldades de reunião de todos os docentes envolvidos na jornada única, professores polivalentes e especialistas, em função de incompatibilidade de horário;

A baixa produtividade das reuniões de trabalho durante as HTPs, às vezes realizadas com professores cansados e sem a presença do professor coordenador do $\mathrm{CB}$, que assumia a regência de classe naquele horário (DURAN, 2003, p.73).

Algumas pesquisas, segundo Duran (2003), constataram que a implantação da Jornada Única não melhorou significativamente o rendimento escolar dos educandos, não eliminou o gargalo na passagem da $1^{\mathrm{a}}$ para a $2^{\mathrm{a}}$ série, mas o transferiu para a $3^{\mathrm{a}}$ série. Também não se perceberam resultados mais expressivos nas $3^{\mathrm{a}}$ e $4^{\mathrm{a}}$ séries, cujo rendimento demonstrava-se em declínio, não revelava uma melhoria que se esperava com as modificações efetuadas.

Por outro lado, vários avanços foram alcançados com a Jornada Única, como a ampliação da permanência da criança na escola, o espaço para reuniões de formação em serviço dos professores, a presença de um Coordenador Pedagógico em cada escola para orientar e organizar o trabalho pedagógico, entre outros.

\section{A Escola Padrão - Governo Fleury (de 15 de março de 1991 a 01 de janeiro de 1995)}

De 1991 a 1995, o Estado de São Paulo esteve sob o comando do governador Antonio Fleury Filho, que em seu programa de governo objetivou recuperar o padrão de qualidade da Escola Pública paulista. Evidencia-se o paradigma da liberdade econômica, da eficiência e da qualidade ordenando os discursos político-educacionais.

Nesse sentido, segundo esse discurso, ampliou-se o ano letivo de 180 para 200 dias letivos, por meio do Decreto $\mathrm{n}^{\mathrm{o}}$ 34.035, de 22 de outubro de 1991, o Projeto Educacional Escola Padrão, que visava modernizar as escolas e propiciar aos alunos uma educação de qualidade, entendendo que: 
A palavra padrão, aplicada à escola que queremos, tem o sentido oposto à padronização. Ela deve ser o reverso da escola uniforme, burocrática, rígida e anônima. $\mathrm{O}$ que todos estamos determinados a construir é um novo padrão de qualidade (SÃO PAULO, SEE, 1991).

Para alcançar a qualidade de ensino desejada e explícita no projeto, as diretrizes para organização das Escolas Padrão estavam fundamentadas na autonomia da escola e na descentralização do sistema educacional, com prioridade nos órgãos intermediários e na unidade escolar, sob uma nova concepção de gestão administrativa, financeira e pedagógica, entendendo que:

A Escola-Padrão deve ser capaz de gerenciar efetivamente os serviços por ela prestados, tornando-se uma unidade de decisão (portanto, com poder para definir quais são e como empregar seus recursos); planejar sua atividade com elevado grau de liberdade, estruturando-se para controlar a sua forma de operação; e avaliar os resultados obtidos, bem como identificar as possíveis formas de aprimorá-los (SÃO PAULO, SEE, 1992, p.4).

Nessa perspectiva, várias mudanças e inovações foram implantadas nas escolas que participaram do projeto, buscando oferecer às unidades escolares uma maior autonomia pedagógica e administrativa. No âmbito das questões referentes ao processo de ensinoaprendizagem, as escolas passaram a elaborar seu Projeto Pedagógico, planejando e implantando ações relacionadas às questões do ensinar e do aprender de acordo com os problemas e necessidades que se evidenciavam em sua realidade especifica. $\mathrm{O}$ corpo docente teve a liberdade de escolher as práticas, técnicas e metodologias que mais se ajustassem à escola em que atuavam e aos seus alunos.

Já a descentralização das verbas no âmbito da organização administrativa possibilitou às escolas gerenciar os recursos financeiros de forma mais adequada ao seu funcionamento, o que foi encaminhado pela participação da comunidade escolar, por meio do Conselho de Escola, da Associação de Pais e Mestres e do Grêmio Estudantil. Manifestando-se, portanto o discurso da liberdade econômica. Para que se possa entender os anseios e expectativas dos sujeitos, nesse contexto, é necessário pensar o discurso educacional, como um dos discursos constituintes, dotado de maior autonomia e que conferia "...sentido aos atos da coletividade, aquilo para além dos quais não há mais do que o indizível. Zonas de falar entre outras e falas que se pretendem acima de qualquer outra" (MAINGUENEAU, 2008, p. 138).

O processo de possibilitar à escola uma maior autonomia veio acompanhado de mudanças na estrutura organizacional da escola, com alterações no Horário de Trabalho Pedagógico - HTP, na jornada dos professores, entre outros aspectos.

O HTP que, na Jornada Única, atendia apenas aos docentes que atuavam na primeira e segunda séries do Primeiro Grau, no Projeto Escola Padrão, ampliou sua abrangência para todos os professores da unidade escolar, passando a ser incorporado na jornada de trabalho do professor. As reuniões pedagógicas passaram a ter, no mínimo, duas horas consecutivas, em dia e horário pré-estabelecidos.

Para orientar o trabalho pedagógico, a escola passou a contar com uma equipe de coordenadores pedagógicos eleitos por seus pares. Essa equipe era composta com o escopo de atender às necessidades da escola, e podia se efetivar de diferentes formas: Coordenador por segmento de Cursos ou Áreas; Coordenador do Ensino Fundamental; Coordenador do 
Ensino Médio; Coordenador do Período Noturno; Coordenador da Habilitação Específica do Magistério - HEM; Coordenador do CIC - Centro de Informação e Criação.

A jornada de trabalho dos professores também sofreu alterações, mudança esta que tinha como objetivo fixar os docentes em uma única unidade escolar e proporcionar mais tempo para os trabalhos pedagógicos e para a formação contínua dos mesmos.

Assim, os professores PIII, categoria esta que abrangia os professores especialistas nas Escolas Padrão, passaram a compor sua jornada de trabalho em duas situações distintas, de acordo com a distribuição de suas aulas, sendo que: para os professores do período diurno - jornada integral de 40 horas semanais, com 25 horas-aula em sala de aula e 7 horas em atividades pedagógicas, além de 8 horas em local de livre escolha; para professores do período noturno - jornada integral de 30 horas-aula semanais, sendo 20 horas em trabalho docente em sala de aula, 4 horas em atividades pedagógicas e 6 horas em horário e local de livre escolha.

Também foram realizadas alterações no espaço físico das Escolas Padrão, que passaram por reformas para ampliar e adequar os prédios escolares ao novo modelo pedagógico, como salas de TV e vídeo, auditório, bibliotecas e outras dependências.

Na formação contínua dos professores várias ações foram efetivadas, tendo a FDE - Fundação para o Desenvolvimento da Educação - a responsabilidade de organizar e implantar programas de formação. Vários projetos foram desenvolvidos, alguns descentralizados, que se efetivaram por meio das Oficinas Pedagógicas, instaladas nas Delegacias de Ensino. As oficinas propiciaram encontros e cursos de formação aos professores, e outras desenvolvidas pela própria FDE, que oferecia cursos de formação para professores, coordenadores pedagógicos e diretores das Escolas Padrão, segundo os preceitos do projeto.

Porém, no decorrer do processo, as ações desenvolvidas em formação continuada passaram a evidenciar alguns problemas, pois:

\begin{abstract}
Muitos materiais não foram utilizados porque desconhecidos, em decorrência da desarticulação entre a FDE e a CENP. Os cursos propostos pela FDE para serem desenvolvidos pelos capacitadores que formou, nem sempre puderam ser realizados nas Delegacias de Ensino por razão de horário inadequado aos professores, imposto pelos capacitadores. (ALBUQUERQUE, 1997, p.97).
\end{abstract}

O Projeto Educacional Escola Padrão passou a ser foco de muitas críticas de professores e funcionários da educação paulista, pois o objetivo inicial de implantar o projeto em toda rede estadual de ensino não foi alcançado, chegando, ao final do governo Fleury, a apenas $30 \%$ das escolas da rede incorporadas ao projeto. As críticas mais frequentes reportavam-se ao tratamento diferenciado que as Escolas Padrão recebiam, ficando o restante da rede sem recursos para desenvolver seus projetos e sem as condições de trabalho que as escolas que participavam do projeto tinham.

O Projeto Escola Padrão foi encerrado na gestão que sucedeu o Governo Fleury, com a eleição de Mário Covas para o Governo do Estado de São Paulo.

\title{
A reorganização do sistema educacional - Governo Covas (de 01 de janeiro de 1995 a 01 de janeiro de 1999 e de 01 de janeiro de 1999 a 06 de março de 2001)
}

Com a eleição de Mário Covas, o sistema educacional paulista passou por mudanças estruturais e organizacionais intensas que levaram a movimentos de repúdio e de adesão. Entre as várias alterações realizadas no governo Covas, privilegiaram-se as ações 
que tiveram um maior impacto na Rede de Ensino paulista e no trabalho dos docentes em sala de aula, que são: a implantação do Horário de Trabalho Pedagógico Coletivo - HTPC e da Coordenação Pedagógica; a reorganização da Rede Pública de Ensino do Estado de São Paulo; o incremento da municipalização do Ensino Fundamental no Estado; a reorganização curricular; o Projeto Correção de Fluxo Escolar.

Com a implantação do Horário de Trabalho Pedagógico Coletivo - HTPC e da Coordenação Pedagógica - com o fim do Projeto Educacional Escola Padrão, o governo estadual passou a ampliar o espaço para a realização das reuniões de HTP para todos os professores do ensino fundamental.

Em 1997, os HTPs se tornaram obrigatórios para todos os professores que atuavam com as quatro séries inicias do Ensino Fundamental e, para os demais professores das séries subsequentes, a participação nas reuniões pedagógicas era optativa.

Essa situação se alterou em 1998, quando as reuniões passaram a receber a denominação de Horário de Trabalho Pedagógico Coletivo - HTPC - espaço este que objetivava o desenvolvimento de projetos e a formação contínua dos docentes em serviço. Estes deveriam ser realizados com o coletivo dos professores a fim de se planejarem, articularem e integrarem ações pedagógicas na unidade escolar. Os HTPCs passaram a ser extensivos a todos os professores do Ensino Fundamental, sendo as horas das reuniões incorporadas em sua jornada de trabalho.

Também houve a designação de um Professor Coordenador Pedagógico - PCP, para todas as escolas, profissional este que passou a ser responsável pela organização das atividades pedagógicas desenvolvidas na escola e pelo planejamento e desenvolvimento dos HTPCs. A escola que tinha dez salas ou mais no período noturno passou a ter um PCP específico para atender às necessidades do período.

A ampliação dos HTPCs e dos PCPs para todas as escolas era uma reivindicação histórica do magistério paulista, defendida por sindicatos da classe e por professores como um dos aspectos que colaborariam para o aprimoramento do trabalho pedagógico e para a melhoria da qualidade do ensino que, em muitas escolas, não aconteceu, pois:

[...] o cumprimento dessa imprescindível demanda pelo trabalho coletivo na escola esbarra decisivamente nas condições de trabalho dos professores "especialistas". E mais, a maioria das vezes essas reuniões são feitas por professores famintos e/ou cansados, pois apenas nos intervalos entre os três períodos é que permitem a existência de salas vazias ou professores sem atividades letivas (DIAS-DA-SILVA e LOURENCETTI, 2002, p.31).

Outros pontos polêmicos, como a progressão continuada, a rotatividade dos professores, ocultavam ainda mais o desenvolvimento das ações de muitos Coordenadores Pedagógicos, comprometendo a continuidade do trabalho no desenvolvimento de projetos e na formação em serviço dos professores.

Esses discursos sustentam-se em sistemas de valores que, por sua vez, reproduzem não só discursos políticos, mas também outros tantos sobre cidadania, ética, vontade política, além de discursos político-salariais, de classe etc.

Para a leitura de alguns aspectos do discurso educacional, parte-se do pressuposto de que as diferentes linguagens que constituem os discursos representam lugar de conflito, de confronto, de ideologia e não podem ser estudadas sem vínculos com suas condições de produção.

A Reorganização da rede física, no início da gestão de Mário Covas, foi um processo iniciado em 1995. Além disso, também, procedeu-se ao cadastramento geral de 
alunos do Estado de São Paulo, para "mapear" as matrículas. Criou-se para isso, um sistema de informações que permitiu à Secretaria da Educação verificar a localização dos equipamentos escolares e dos recursos materiais e humanos disponíveis na Rede Pública de ensino.

Em 1996, as escolas foram reorganizadas em quatro situações distintas: escolas para alunos de $1^{\text {a }}$ a $4^{\text {a }}$ séries do Ensino Fundamental; escolas para alunos de $5^{\text {a a }} 8^{a}$ séries do Ensino Fundamental; escolas para alunos de $5^{\mathrm{a}}$ a $8^{\mathrm{a}}$ séries do Ensino Fundamental e do Ensino Médio; escolas para alunos do Ensino Médio.

O governo justificou a necessidade de reorganizar a rede física com a afirmação de que as unidades escolares não eram adequadas ao ensino diferenciado para crianças e adolescentes, o que, além de dificultar o atendimento das especificidades dos alunos, provocava a dispersão de recursos e impossibilitava muitos professores de fixar sua jornada de trabalho em uma única escola.

A reorganização da rede física de ensino foi muito criticada por pais, alunos, professores e entidades representativas do magistério, principalmente por ter sido idealizada e implementada sem a consulta da população interessada, pois as mudanças efetivadas interferiram na vida e na organização da rotina das famílias dos alunos e desencadeou a demissão de muitos professores, visto que, com a reorganização houve a redução de 30 para 25 horas aula semanais para os alunos da Rede Estadual de Ensino paulista.

Os pontos centrais em que se apoiou e se justificou a necessidade de se reorganizar a rede física não se concretizaram, ou seja, não houve uma reorganização dos espaços escolares, com mobiliário e materiais didáticos para atender às crianças e aos adolescentes em suas necessidades específicas.

Com isto, não houve a melhoria anunciada que o projeto desencadearia. Muitos críticos à proposta na época já denunciavam, que a reorganização estaria apenas preparando a rede para a municipalização do Ensino Fundamental - ciclo I ( $1^{\mathrm{a}}$ a $4^{\mathrm{a}}$ séries).

A reorganização da Rede Pública de Ensino do Estado de São Paulo abriu caminho para o Programa de Municipalização da Rede de Ensino, inicialmente explicitado pelo Decreto $n^{\circ} 40673 / 96$ e alterado pelo Decreto $n^{\circ} 40889 / 96$, que instituiu o Programa de Ação de Parceria Educacional Estado-Município. Este norteou o processo de municipalização por meio de um Termo de Convênio, que instituiu um plano de trabalho do município com objetivos e metas e um cronograma de desembolso financeiro para a efetivação do processo de municipalização. Essas ações propostas partiam da premissa de que:

A descentralização, ao permitir maior acompanhamento da escola e do trabalho de diretores e professores palas comunidades locais, pode ser o caminho mais seguro para reduzir significativamente o alto grau de ineficiência e ineficácia das ações desencadeadoras, devido à superposição de competências dos órgãos centrais e à ausência de mecanismos de controle e avaliação das ações (SÃO PAULO, SEE, 1997, p.13).

Este programa, para incentivar a municipalização do Ensino Fundamental no Estado de São Paulo, se fortaleceu com a publicação da Emenda Constitucional $n^{\circ} 14$, de setembro de 1996 e com a implantação do Fundão - Fundo de Manutenção e Desenvolvimento do Ensino Fundamental e Valorização do Magistério, legislação esta que revela: 
Esta sincronicidade mostra como o Governo do Estado está afinado com as diretrizes federais, tanto no que diz respeito às diretrizes educacionais, quanto no contexto maior de redefinição do papel do Estado (BIOTO, 2000, p.180).

Segundo Oliveira (1999), as medidas implementadas no sistema educacional, nos âmbitos federal e estadual a partir de 1995, foram duramente criticadas pelos que identificavam aí a adequação das políticas educacionais aos preceitos neoliberais que objetivam a redução do papel do Estado, buscando distribuir as responsabilidades sociais, utilizando, para isso:

Discursos de que a educação vai mal, porque se gasta mal seus recursos, estaria, segundo os críticos do governo, servindo para justificar o "enxugamento" e esvaziamento das funções sociais do Estado (OLIVEIRA, 1999, p.29).

Quanto à Reorganização curricular, em 15 de janeiro de 1998, a Resolução $\mathrm{n}^{\circ} 4$ dispõe sobre as normas para o funcionamento do Regime de Progressão Continuada na Rede Pública de Ensino paulista em dois ciclos, orientando as unidades escolares a reorganizar a grade curricular, com a alteração do tempo de duração e a quantidade de aulas das disciplinas no ensino fundamental.

Houve uma diminuição no número de aulas da grade curricular, priorizando-se a Língua Portuguesa e a Matemática, ficando a Educação Artística e a Educação Física, disciplinas que antes tinham duas aulas semanais para cada série do ensino fundamental, ciclo II ( $5^{\mathrm{a}}$ a $8^{\mathrm{a}}$ séries $)$, divididas em três aulas por série, cabendo à escola definir a distribuição das aulas na grade curricular.

Além as mudanças até aqui destacadas, propostas estas que, em grande parte, visavam reorientar os recursos da educação, o governo estadual cria o Projeto Correção de Fluxo Escolar, que tem como objetivo corrigir a distorção entre a idade e a série que, segundo a Secretaria da Educação, atinge aproximadamente $30 \%$ dos alunos da Rede Pública de Ensino paulista, situação esta que comprometia a autoestima dos educandos e propiciava um desperdício de recursos públicos.

Procurando alterar esta realidade, algumas medidas foram tomadas com vistas a barrar a reprovação e reorientar a trajetória escolar dos alunos que estavam fora do ano de escolaridade condizente com sua idade, entre elas: classes de aceleração, recuperação de férias e regime de progressão continuada.

O Projeto Classes de Aceleração objetivou corrigir a trajetória escolar dos alunos que ultrapassassem em dois anos ou mais da idade prevista para a série, em que se encontravam matriculados. Em 1996, algumas escolas participaram de um projeto piloto, que mais tarde foi se ampliando, chegando em 1998 a atingir 4.202 escolas e aproximadamente 210.000 alunos.

As turmas que passaram a compor o projeto tinham condições especiais para o desenvolvimento de uma proposta pedagógica diferenciada, com salas compostas por 20 a 25 alunos e professores indicados pelos diretores das escolas. Tinham como parâmetro a competência do docente e a predisposição em assumir o desafio de atuar com crianças e jovens considerados como alunos difíceis, que por problemas disciplinares, ou por desinteresse pelo estudo e/ou dificuldade de aprendizagem que apresentavam.

Foi produzido um material pedagógico específico para atender ao projeto e uma atenção especial para as disciplinas Educação Artística e Educação Física, que tinham um 
apoio financeiro para a aquisição de materiais com fins a atender as necessidades de cada escola.

O Projeto Classes de Aceleração visava reorientar a trajetória dos estudantes que estavam em defasagem, mas outras medidas foram tomadas procurando evitar que esta situação se repetisse. Foi nesse contexto que o Projeto "Escola nas Férias: você estuda um mês e ganha um ano", foi anunciado em dezembro de 1996 e realizado no mês de janeiro dos anos subsequentes.

Poderiam participar do projeto os alunos reprovados no final do ano letivo, devendo, no mês de janeiro, assistir a cinco aulas diárias e participar das atividades de recuperação propostas. Esse projeto causou reações dos professores e de suas entidades representativas, sendo que:

Já nos documentos da APEOESP, assim como nos posicionamentos de seus representantes pela imprensa, ficou marcada posição contrária à recuperação de férias. Chegou-se a pedir aos professores que boicotassem o projeto e não se apresentassem para ministrar as aulas (OLIVEIRA, 1999, p.45).

A falta de respeito para com o processo pedagógico, desconsiderando o trabalho desenvolvido pelos professores durante o ano letivo e o descompromisso com a formação do aluno, foram os aspectos mais criticados pelos professores e pelos sindicatos da classe que, segundo alguns críticos à proposta, a aprovação em massa que o projeto desencadeou estava vinculada, única e especificamente, ao discurso de contenção de gastos.

A situação se agravou ainda mais, quando, em janeiro de 1998, a Secretaria da Educação ampliou a possibilidade de participação dos alunos na recuperação de férias, não limitando mais o número de componentes curriculares em que o discente tivesse sido reprovado e desconsiderava o número de ausências nas aulas regulares no ano anterior.

Sobre o Regime de Progressão Continuada, foi o mais controverso e criticado projeto para conter os índices de reprovação e de evasão escolar, implantado a partir de 1998.

Para desenvolver o projeto, a Secretaria da Educação organizou o ensino fundamental em dois ciclos de aprendizagem, considerando o ciclo I para os alunos de $1^{\mathrm{a}}$ a $4^{\text {a }}$ séries, e o ciclo II, de $5^{\text {a }}$ a $8^{\text {a }}$ séries. No Ensino Médio, os alunos fariam estudos paralelos nas disciplinas em que fossem reprovados, acompanhando sua turma num período de três anos.

Ao defender a não-reprovação, em dois ciclos distintos no Ensino Fundamental, o governo paulista considerava que a avaliação e a recuperação da aprendizagem devem ser contínuas, cujo objetivo é o sucesso do aluno.

Embora a progressão continuada seja defendida por muitos estudiosos, várias críticas têm sido feitas na experiência implantada na Rede Pública de Ensino paulista. Paro (2003) destaca que uma concepção de desenvolvimento da aprendizagem nessa perspectiva demanda várias outras ações paralelas para que se tenha o resultado esperado.

Nesse sentido, o número excessivo de alunos em sala de aula, as condições salariais e de trabalho em que os professores atuam, a falta de participação dos docentes nas discussões das reformas implantadas, são aspectos que, se fossem melhor encaminhados, concorreriam para um melhor desenvolvimento de um regime de progressão continuada.

Também preocupante é a resistência que muitos professores têm com relação ao regime de progressão continuada, sendo que muitos docentes consideram que, na realidade, o que o governo paulista implantou foi um regime de promoção automática. Verifica-se 
que os professores são sujeitos constituídos, segundo o discurso da educação tradicional, em que naturalmente aqueles que não são considerados aptos, devem ser retidos.

Nesse contexto, também merece destaque a pesquisa realizada por Paro (2001), em uma escola pública paulista, onde constatou, entre outros aspectos, a existência de um apego dos professores à reprovação, mas que este apego está relacionado a determinantes institucionais, ou seja:

[...] a maior ou menor propensão para a resistência à aprovação é sensível à forma mais ou menos adequada das condições de trabalho na escola e no modo como esta se encontra. Para sintetizar a ação desses determinantes, pode-se considerar três maneiras pelas quais os fatores institucionais atuam na indução dos educadores a resistirem à promoção dos alunos: a pressão das condições materiais escolares adversas à realização de um ensino de qualidade; a prevalência da reprovação como estruturante do ensino; e a ausência de medidas do sistema de ensino tendentes a facilitar a aceitação da aprovação. (PARO, 2001, p.98).

Essa discussão está em curso, pois grande parte dos estudiosos defende a importância da progressão continuada como forma de propiciar uma educação inclusiva e de qualidade à população, porém, muitos aspectos devem ser revistos para que, efetivamente, esses preceitos sejam alcançados.

$\mathrm{O}$ que se evidencia, neste projeto e em tantos outros, que foram desenvolvidos pelos sucessivos governos paulistas, é a falta de espaço participativo dos professores nas discussões e na elaboração das propostas que orientaram a Educação no Estado de São Paulo nos últimos anos. A realidade vivenciada pelos docentes, segundo a sua ótica, não foi valorizada, os professores ficaram à margem do processo decisório, apenas cumprindo determinações que nem sempre se reportavam à realidade da Escola Pública paulista e às reais necessidades dos docentes e dos alunos.

Ao se tomar como exemplo, a reconstrução do sentido do discurso políticoeducacional, segundo uma análise das modalidades do discurso, apresenta-se a seguir (Fig.1.), o modelo de Pais (1997), que é uma descrição do universo do discurso da Vontade Política. Neste modelo, baseado na lógica de Aristóteles, formalizam-se valores da vontade política, do modo do querer e se caracteriza uma tensão dialética entre o poderfazer-querer e o poder-fazer-não-querer:

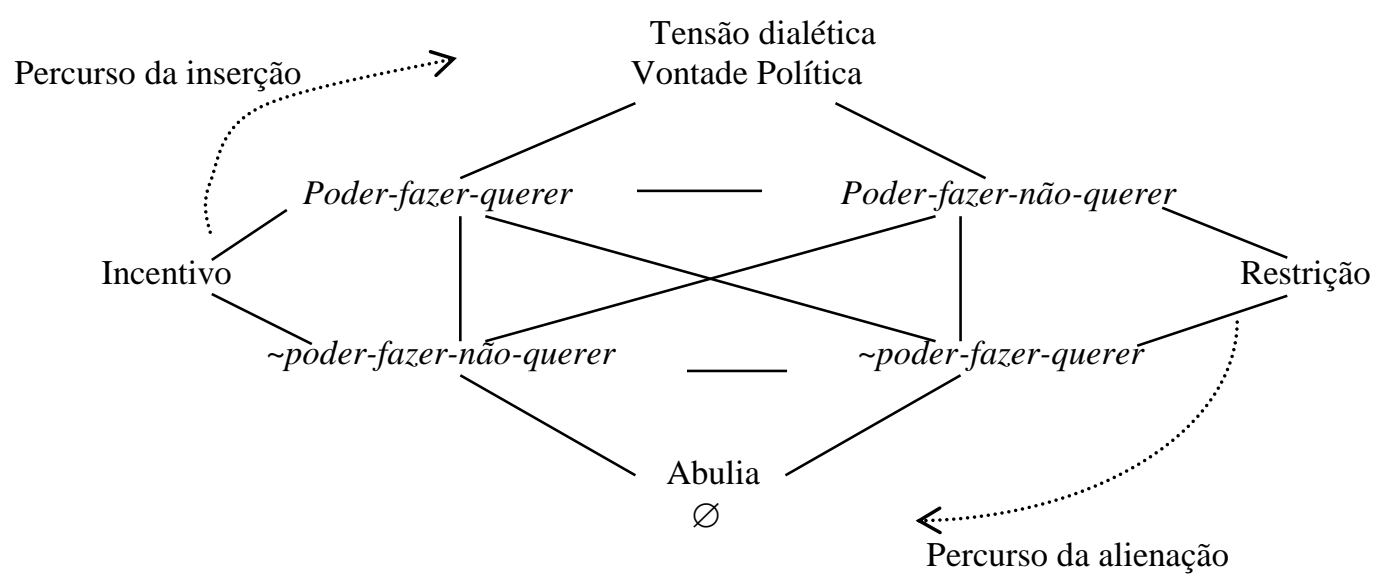

Fig.1. Universo do Discurso da Vontade Política (PAIS, 1997, p. 328) 
Foi possível essa formalização de valores no discurso político-educacional, em que, com a constituição da Lei, de um lado tem-se o Incentivo, e de outro, a Restrição. A ausência de vontade é a Abulia, que se define a partir de um não-poder-fazer-não-querer e um não-poder-fazer-querer. Por exemplo, um "professor" que não é incentivado ao acesso à rede de informação está num processo de alienação.

Essas linguagens devem ser estudadas de forma interdisciplinar, crítica e não acabada, em constante construção e com levantamento de problemas, sem eliminar contradições que devem emergir na materialidade de diferentes discursos. A subjetividade é constituída por linguagens que produzem sentidos e produzem processos de identificação dos sujeitos e, como menciona Orlandi precisa-se “...perceber que não podemos não estar sujeitos à linguagem, a seus equívocos, sua opacidade” (ORLANDI, 2000, p. 20).

\section{Considerações Finais}

Diante dessas reflexões sobre o processo histórico da educação paulista dos últimos governos, da década de 1980, para a situação atual, manifestaram-se discursos que reforçaram sistemas de valores mundiais.

A lógica dos paradigmas que ditaram as mudanças, do capitalismo concorrencial global e do paradigma da liberdade econômica, da eficiência e da qualidade, encaminha o novo modelo societário e são necessárias novas reformulações na educação. No entanto, segundo Libâneo, Oliveira e Toschi (2009, p. 106), a compreensão histórica dessa lógica capitalista-liberal revela um caráter conservador-elitista, pois em relação à educação, essa orientação política do neoliberalismo de mercado mostra um discurso de crise e de fracasso da escola pública, que é decorrente de uma incapacidade administrativa e financeira do Estado para gerir o bem comum. Contraditoriamente, discute-se o problema da requalificação do trabalhador, por isso, a educação básica, melhor dizendo, o ensino fundamental ganha centralidade nas políticas educacionais. Seguem as orientações do Banco Mundial, que refletem a tendência da nova ordem econômica mundial, o avanço das tecnologias e da globalização.

\section{REFERÊNCIAS}

ALBUQUERQUE, Helena M. de P. A Escola Padrão no Estado de São Paulo: um referencial de gestão para uma educação democrática. Tese (Doutorado em Educação e Currículo). Pontifícia Universidade Católica de São Paulo. São Paulo, 1997.

ALVAREZ, Marcos César. Michel Foucault e a 'Ordem do Discurso'. In: CATANI, Afrânio Mendes e MARTINEZ, Paulo H. (orgs). Sete Ensaios sobre o Collège de France. Coleção Questões da Nossa Época. São Paulo: Cortez, 1999.

BIOTO, Patrícia A. Aspectos econômicos e políticos da municipalização do ensino: o caso de São Paulo nos anos 80 e 90. Dissertação (Mestrado em Educação). Universidade Federal de São Carlos, 2000.

DIAS-DA-SILVA, Maria G. F. e LOURENCETTI, Gisela do C. A voz dos professores e algumas reformas educacionais nas séries iniciais do ensino fundamental. In: SAMPAIO, Maria das M. F. (org). O cotidiano escolar face às políticas educacionais. Araraquara: JM Editora, 2002. 
DURAN, Marília C. G. A organização do ciclo básico e a concepção de alfabetização. In: PALMA FILHO, J. C.; ALVES, M. L.; DURAN, M. C. G. Ciclo básico em São Paulo. São Paulo: Xamã, 2003.

FOUCAULT, Michel. Microfísica do poder. Rio de Janeiro, Graal, 1998. As Palavras e as coisas. São Paulo: Martins Fontes, 1995

LIBÂNEO, José Carlos; OLIVEIRA, João Ferreira de; TOSCHI, Mirza Seabra. Educação Escolar: políticas, estrutura e organização. $7^{\text {a }}$ ed. São Paulo: ed. Cortez, 2009.

MACHADO, Roberto. Por uma genealogia do poder. In: FOUCAULT, Michel. Microfísica do Poder. Rio de Janeiro: Graal, 1998.

MAINGUENEAU, D. Cenas da Enunciação. São Paulo: Parábola Editora, 2008.

OLIVEIRA, D. A. Educação básica e reestruturação capitalista: gestão do trabalho e da pobreza. Tese (Doutorado em Educação). Universidade de São Paulo. São Paulo, 1999.

PAIS C. T. (1997), “Conceptualização, Denominação, Designação: relações”. In. Revista Brasileira de Linguística. Vol. 9, São Paulo, Plêiade.

Conditions sémantico-syntaxiques et sémiotiques de la productivité systémique, lexicale et discursive. Thèse de Doctorat d'État ès-Lettres et Sciences Humaines. Paris, Université de Paris-Sorbonne/Lille, Atélier National de Reproduction des Thèses, 1993.

PALMA FILHO, J. C. Reorganização do ensino fundamental na rede de ensino pública paulista: política, ideologia e memórias . In: PALMA FILHO, J. C.; ALVES, M. L.; DURAN, M. C. G. Ciclo básico em São Paulo. São Paulo: Xamã, 2003.

PARO, Vitor H. Reprovação escolar: renúncia à educação. São Paulo: Xamã, 2001.

RABINOW, P; DREYFUS, H. Michel Foucault. Uma trajetória filosófica. Rio de Janeiro, Forense, 1995.

SÃO PAULO (Estado). A escola que faz a diferença. São Paulo: Secretaria de Estado da Educação, 1997.

Orientações para o processo de implantação do Projeto Escola Padrão. São Paulo: Secretaria de Estado da Educação, 1992.

Programa de reforma do ensino público do Estado de São Paulo. São Paulo: Secretaria de Estado da Educação, 1991.

\section{Notas}

${ }^{1}$ Doutor em Educação pela PUC - SP. Professor do Programa de Mestrado em Políticas Públicas da da Universidade de Mogi das Cruzes, SP. Integrante do Grupo de Pesquisa em Políticas Culturais e Educação: estudo dos discursos, multiculturalismo e diversidade.

${ }^{2}$ Doutora em Semiótica e Linguística Geral, pelas USP - SP. Professora do Programa de Mestrado em Políticas Públicas da Universidade de Mogi das Cruzes, SP. Líder do Grupo de Pesquisa em Políticas Culturais e Educação: estudo dos discursos, multiculturalismo e diversidade.

Recebido: $\quad$ janeiro-14 Aprovado: novembro-14 